\title{
No voy a odiar
}

Izzeldin Abuelaish

Reseña escrita por el profesor Marek Glezerman *

* Director del Hospital para Mujeres y director adjunto de Rabin Medical Center, Israel

(texto adaptado de una entrevista concedida a Rally Armstrong).

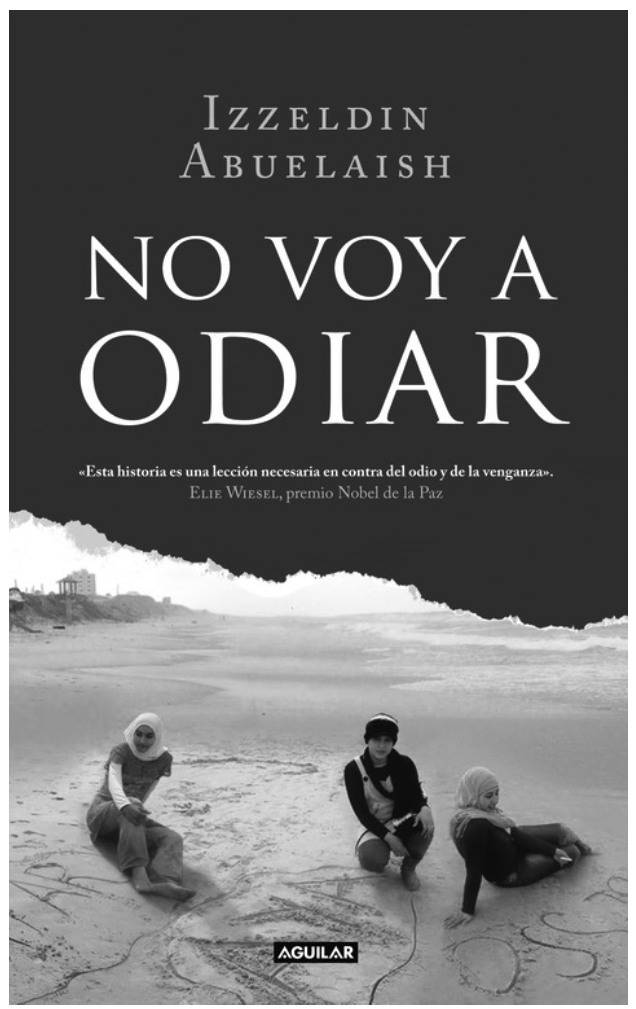

A principios de la década de 1990, cuando yo era jefe del Servicio de Obstetricia y Ginecología en Soroka Medical Center de Beerseba, Israel, el doctor Izzeldin Abuelaish se puso en contacto conmigo para hacerme una consulta sobre unos pacientes a los que estaba tratando en la Franja de Gaza. A partir de aquel momento comenzó a traerme a sus pacientes a mi consulta después del trabajo. Eran en su mayoría parejas con problemas de fertilidad a las que yo atendía normalmente de forma gratuita. Con el tiempo llegué a conocer bien a Izzeldin, médico dedicado y ser humano compasivo, y quedé impresionado por la profunda empatía que llegaba a tener con sus pacientes. También descubrí que su modo de enfrentarse y de entender la vida y el mundo en general era excepcional. Viajar desde Gaza al hospital Soroka no es fácil. Nunca se sabe si la frontera va a estar cerrada ni si podrás salir después. Dado que tanto él como sus compatriotas palestinos experimentan esta frustración a diario, me parecía extraordinario que Izzeldin nunca extendiese 
de modo general sus quejas. Nunca lo oí condenar las injusticias que había sufrido de un modo genérico, sino siempre específico, dirigiendo sus críticas a una situación en concreto. Esta postura también se refleja en su actitud optimista de enfrentarse a la vida: parece incapaz de albergar un pesimismo existencial o clase alguna de desesperanza. Jamás se regodea en pensar «lo que podría haberse hecho en el pasado», sino que sólo piensa en lo que se podrá hacer en el futuro. Es un hombre que siempre mira hacia el porvenir, que siempre está lleno de esperanza, algo bastante difícil en este mundo y particularmente en el suyo.

Otro de los rasgos de carácter más notables en Izzeldin es su deseo constante de ampliar sus conocimientos. Siempre ha intentado completar su formación y nunca se ha cansado de aprender y desarrollar sus capacidades. Cuando lo conocí, había estudiado obstetricia y ginecología en Arabia Saudí, pero soñaba con hacer su residencia en Israel. Para mí fue un gran reto conseguir que fuese el primer médico palestino que completara su residencia en nuestro país. Los programas para la residencia de los médicos en Israel son muy intensos y alcanzan elevadas cotas de calidad. Teniendo en cuenta todas las dificultades a las que tenía que enfrentarse viviendo en Gaza, el mayor obstáculo no era si tendría formación suficiente para hacerse acreedor del puesto, sino si sería capaz de llevarlo a buen término, dado que nunca iba a poder estar seguro de si cruzaría o no la frontera para encargarse de las tareas que lo esperarían aquí.

En 1995, más o menos cuando yo pasé a ocupar un puesto de responsabilidad en otro hospital, Izzeldin fue admitido en el programa de residencia en obstetricia y ginecología en Soroka Medical Center. Se trataba de una residencia diseñada a medida y destinada no a aprobar un examen sino a ampliar el currículum. Contra todo pronóstico consiguió completarla con todas sus rotaciones en distintos servicios, con los problemas fronterizos diarios, la barrera del idioma y el inconveniente de los horarios. Por ejemplo: si un interno no se presenta a la hora debida, alguien debe hacer el turno por él apenas sin tiempo para organizarlo, y a nadie le gusta hacer eso. En función de lo que ocurriera en la frontera había ocasiones en las que Izzeldin y otros palestinos de Gaza al igual que él no podían entrar en Israel. Otras veces, después de haber hecho el turno de noche, no se le permitía volver junto a su familia en Gaza. Pero él nunca se rindió. Completó el programa de seis años, adquirió un dominio absoluto del hebreo y consiguió llegar a ser un competente ginecólogo y obstetra.

Izzeldin tenía todas las razones del mundo para sentirse frustrado, desilusionado y ofendido por el entorno en el que le ha tocado vivir, pero él no es así. A pesar de todo lo que ha visto y ha tenido que soportar, su creencia en la coexistencia y en el proceso de paz entre palestinos y judíos sigue firme. Él no considera a Israel como una entidad monolítica en la que todo el mundo es igual. Conoce a muchos israelíes, algunos de los cuales han llegado a ser amigos suyos, que no desprecian a todos los palestinos por considerarlos terroristas, y conoce a muchos palestinos que de la misma manera no califican a todos los israelíes como ocupantes de la extrema derecha. Izzeldin cree que hay dos pueblos que quieren vivir en paz y que están hartos de guerra y sangre. Tiempo atrás la gente corriente de ambos lados era más militante y los gobiernos se sentían quizá más inclinados a buscar una solución. Sin embargo, él cree que la situación presente es la contraria: la gente, tanto israelíes como palestinos, quiere vivir en paz, tener una vida decente, un techo sobre la cabeza y seguridad para sus hijos. Son sobre todo los líderes de sus comunidades los que se empeñan en seguir peleando las batallas inconclusas de ayer. 
Hemos seguido manteniéndonos en contacto a lo largo de los años. Lo he visto en conferencias y, qué duda cabe, hemos hablado sobre el conflicto en Oriente Próximo y las posibilidades de que llegue la reconciliación. Ambos somos optimistas. Ni él ni yo creemos que los obstáculos ideológicos que nos impiden encontrar un ámbito común en el que construir un futuro decente sean insuperables. Cuando nuestros líderes hablan ahora de paz, sus discusiones se centran en el establecimiento de las futuras fronteras geográficas entre Israel y el estado palestino emergente. Y este enfrentamiento puede, debe y será resuelto un día. Sin duda, lo que estoy diciendo peca de simplismo. No podemos obviar el hecho de que muchos fanáticos de ambos lados siguen haciendo todo lo que está a su alcance para tratar de imponer su visión extremista. Pero están en minoría. La verdadera tragedia de nuestros pueblos radica en que prácticamente todo el mundo sabe cuál será el resultado final y, sin embargo, son pocos los que están dispuestos a admitirlo y a actuar en con- secuencia: dos estados vecinos, Jerusalén como ciudad con un estatus especial, el regreso simbólico de unos cientos de miles de refugiados y la compensación por aquellos que no volverán. La tragedia radica en que la necedad de ambos bandos sigue inexorablemente su curso en dirección opuesta a este acuerdo y deja en el camino multitud de bajas tanto judías como árabes. Cuando me preguntan si mi optimismo nace del idealismo o del realismo, les digo que de una mezcla de ambos. Hay que ser realista aunque se sea un idealista. Y se tiene que ser idealista para poder soportar la realidad en que vivimos aquí. Si se juzgaran nuestras vidas sólo por lo que ha ocurrido ayer u hoy, sería imposible levantar la cabeza y mirar hacia el futuro. Y si, por otro lado, sólo miráramos hacia delante, no dejaríamos de tropezar y caminar en círculos.

Izzeldin es realista, sabe bien que no vivimos en un jardín de flores. Pero cree fervientemente que la medicina puede establecer puentes que salven el abismo entre nuestros pueblos. La medicina y la ciencia no conocen límites ni fronteras, ni deberían conocerlos. Cuando investigo un asunto determinado, leo sobre el tema y tomo en consideración la información publicada en muchos sitios: Japón, Siria, Francia, Estados Unidos. Lo único que me importa es la calidad del informe, no de dónde provienen sus autores. En los congresos internacionales nos reunimos con colegas de todo el mundo, a veces de países que no tienen relaciones diplomáticas con nosotros o entre ellos. Cuando inter- vengo en reuniones científicas, los árabes no abandonan la sala del modo en que a veces lo hacen en Naciones Unidas. Si hablo de medicina y ciencia con un colega cuyo país no tiene relaciones diplomáticas con Israel, hablamos como profesionales... aun- que es fácil que lo hagamos también de cuestiones del ámbito personal mientras nos tomamos luego un café. Aceptar distintos puntos de vista es posible si dos personas se conocen.

Izzeldin estuvo de visita en casa unas semanas antes de que el ejército israelí comenzara a bombardear Gaza y más tarde hablamos por teléfono mientras caían las bombas. Le pregunté cómo se las arreglaban para vivir mientras estaban siendo ataca- dos bajo un fuego cruzado y constante con todos sus hijos en casa. Me contestó: "Como todo el mundo: durmiendo todos juntos en la misma habitación. Ponemos unos cuantos nińos contra una pared y al resto contra la otra, de modo que si nos alcanzan no caigamos todos a la vez». El 16 de enero de 2009 tres de sus hijas estaban junto a la pared equivocada. Después de la tragedia ¿quién lo habría culpado si se hubiera dejado llevar por el ansia de venganza y el desprecio?

Un pequeño grupo de israelíes influyentes pidieron una investigación formal del ataque sobre la casa de Izzeldin y el Ministerio de Defensa respondió con rodeos y evasivas. En la 
actualidad un número creciente de voces israelíes, a las que se han sumado cierto número de parlamentarios, están pidiendo lo mismo pero a mayor escala, pero sigue sin ponerse en marcha una investigación formal e independiente por parte de Israel. Lo que las autoridades han ofrecido por el momento no es suficiente. Si una investigación formal llegase a la conclusión de que se cometió un descomunal error, que es lo que parece, el ejército tendría que admitirlo de modo taxativo y sincero... y por supuesto disculparse y asumir sus responsabilidades.

La notable energía de Izzeldin podría haberse transformado en odio, pero no escogió ese camino, sino que, como es habitual en él, redirigió toda esa energía a conseguir vivir en un lugar mejor, algo que él resume en una frase sencilla pero extraordinaria: «Si supiera que el sacrificio de mis hijas iba a ser el último en el camino a la paz entre palestinos e israelíes, podría aceptarlo».

Izzeldin lucha por sus convicciones. Está dedicado en cuerpo y alma a mejorar su entorno a su manera, que es la medicina. Es posible que Albert Schweitzer, por ejemplo, no fuera el médico más aclamado de su tiempo, pero mediante la medicina alertó al mundo del sufrimiento de África. Obligó a la gente a considerar el continente africano desde un ángulo distinto y a comprender lo que es el sufrimiento y lo que los privilegiados deben hacer por los desheredados. Creo firmemente que la principal contribución de Schweitzer a la medicina no fue tanto la ayuda que prestó a miles de africanos sino haber propiciado la sensibilización del mundo desarrollado sobre nuestros hermanos menos privilegiados. Florence Nightingale es otro ejemplo. Consagró su vida a alimentar y mejorar los cuidados médicos que recibían los pobres, y demostró cuál es el papel humanitario de la medicina. Nos enseñó que es necesario anteponer la com- prensión al tratamiento.

Creo que Izzeldin ha mostrado tanta pasión, tanta compasión y tanta dedicación a mejorar la condición humana que por ello sería ya un médico extraordinario. Pero es un hombre que trasciende el ejercicio de la medicina. Para él la medicina es la herramienta que utiliza para ayudar a sus congéneres a comprender mejor los problemas de los demás, a comunicarse mejor, a ayudarnos a vivir juntos. Las muchas mujeres a las que ha tratado o a las que ha ayudado a dar a luz en Soroka, los muchos colegas israelíes con los que ha compartido situaciones estresantes en un ajetreado entorno clínico, que lo han sustituido siempre que lo ha necesitado o a quienes él ha cubierto en otras ocasiones, sus superiores y sus iguales... todos han encontrado en Izzeldin a un médico palestino nacido en el campo de refugiados de Jabalia que trata a sus pacientes con profesionalidad y con compasión, que es un igual entre iguales y que ha sabido hacerse su amigo. Los pacientes palestinos que acuden a Soroka han encontrado médicos y enfermeras israelíes que los tratan con humanidad y en función de su estado de salud y no de su origen. Así es como la medicina tiende puentes entre pueblos divididos.

Hace unos diez años Izzeldin iba a acudir a una conferencia médica en Chipre. Salió de la Franja de Gaza y fue al aeropuerto, pero las autoridades no lo dejaron embarcar por razones de seguridad, así que perdió el vuelo. Tenía un permiso por el que sólo podía salir en un día en concreto y no había otro avión hasta el día siguiente. Tampoco podía quedarse en el aeropuerto, de modo que quedó atrapado en tierra de nadie. La mayoría de personas que conozco se habrían puesto furiosas. Me llamó y yo llamé a algunos amigos para que pudiese tomar el avión que salía al día siguiente. Pasó la noche en nuestra casa. Yo esperaba encontrarme con un hombre enfadado, humillado incluso, pero cuál fue mi sorpresa al descubrir que sólo estaba enfadado con 
el funcionario del aeropuerto, es decir, con una persona individual y no con todos los israelíes. Así es Izzeldin: nunca se deja llevar hasta generalizar. Se limitó a decir: «Ese tipo no sólo ha sido desconsiderado, sino que además está engańado. Se ha comportado de forma grosera porque no entiende nada».

Izzeldin no generaliza como hacemos la mayoría de nosotros. Imaginemos por ejemplo que vamos de vacaciones a Italia y da la casualidad de que contratamos los servicios de un taxista que resulta ser terrible; llegamos al hotel y nos encontramos con un hombre muy desagradable atendiendo la recepción. Volveríamos a casa hablando mal de todos los italianos. Pues Izzeldin nunca reaccionaría así. Tomó el avión al día siguiente atendido por un empleado que no andaba buscando una excusa cualquiera para ensañarse con un árabe.

A veces la ira es importante y debemos tener la posibilidad de enfadarnos. Pero Izzeldin dirige su ira de un modo controlado, sin dejar que se esparza, que lo desborde y que lo distraiga de su verdadero objetivo.

En unas circunstancias muy trágicas Izzeldin ha despertado la atención internacional. Ha sido entrevistado por los principales periódicos, ha aparecido en programas de televisión de gran audiencia y se ha encontrado y ha hablado con los líderes del mundo, y lo más sorprendente de todo ello es que no ha cambiado lo más mínimo.

Últimamente he oído decir a varias personas que es demasiado bueno para ser real. Después de haber perdido a sus hijas ¿̇cómo puede aún hablar de paz y de amor, y seguir teniendo amigos israelíes? Hay quien ha llegado a preguntarse si no se estará aprovechando de su tragedia. Pero yo lo conozco desde hace muchos años y puedo dar fe de que nada podría estar más lejos de la verdad. Su visión de la coexistencia es honda, fuerte, coherente... tan fuerte como para no haberse visto alterada por una tragedia tan desgarradora que resulta difícil imaginar cómo es posible sobrevivirla. Y él sigue adelante.

Izzeldin ha centrado ahora todos sus esfuerzos en crear una fundación en honor a sus tres hijas muertas, destinada a promo- ver las relaciones entre chicas judías y palestinas y a fomentar su educación. Para ello está organizando una escuela dedicada a este fin. Donde quiera que va, con quienquiera que habla, su objetivo es encontrar el modo de tender puentes en una región tan dividida como la nuestra. Por ahora ha conseguido conmover a muchas personas influyentes tanto con su dolor como con su visión del futuro, y sé que no cejará en su empeño. Si hay una sola persona que pueda conseguir poner en marcha este proyecto, esa persona es él. Yo sólo puedo desearle que alcance el éxito.

\section{Referencias}

1. Abuelaish, I. (2011a). I Shall Not Hate: A Gaza Doctor's Journey on the Road to Peace and Human Dignity (2010, Foreword by Marek Glezerman. Maps on pages ix and 64 by Ortelius Design). New York: Walker and Company.

2. Abuelaish, I. (2011b). No voy a odiar. Viaje de un médico de Gaza por el camino de la paz y de la dignidad humana (traducción al español. 